\title{
Interruption of the Connections of the Mammillary Bodies Protects Against Generalized Pentylenetetrazol Seizures in Guinea Pigs
}

\author{
Marek A. Mirski and James A. Ferrendelli \\ Division of Clinical Neuropharmacology, Department of Pharmacology and Department of Neurology and Neurological \\ Surgery, Washington University School of Medicine, St. Louis, Missouri 63110
}

\begin{abstract}
Electrolytic lesions in the anterior and mid-diencephalon and ventral midbrain in guinea pigs were produced to examine the effects of interruption of the fornix (FX), mammillothalamic tracts (MT), and mammillary peduncles (MP), respectively, on the expression of pentylenetetrazol (PTZ) seizures. As a group, all mid-diencephalic lesioned animals had some degree of protection from the electroencephalographic and behavioral convulsant and lethal effects of the drug. Through a composite volume analysis of protected versus unprotected animals, as well as a retrospective comparison between MT and non-MT lesioned animals, it was demonstrated that small mid-diencephalic lesions incorporating only the MTs and their immediate vicinity were capable of completely preventing the convulsant and lethal effects of PTZ. Lesions of the FX and MP were also protective against PTZ seizures but to a lesser degree than the MT lesions.
\end{abstract}

These results demonstrate that the major afferent and efferent connections of the mammillary bodies are involved in expressing PTZ seizure activity and suggest that the MT may be the major pathway mediating paroxysmal activity from brain stem to the thalamus.

The expression of generalized seizures is characterized by bilateral and synchronous activation of cortical and subcortical brain regions. Although the functional anatomy of this convulsive process is yet unclear, substantial evidence suggests that subcortical brain regions, through their widespread cortical connections, play a major role in the propagation and perhaps initiation of these attacks. Early studies demonstrated numerous facilitatory and inhibitory influences on seizure activity in both the brain stem and diencephalon (Morison and Dempsey, 1942; Jasper and Droogleever-Fortuyn, 1946; Hunter and Jasper, 1949; Ingvar, 1955a, b; Ralston and Ajmone-Marsan, 1956; Kriendler et al., 1958; Andy and Mukawa, 1959; Bergman et al., 1963; Guerrero-Figueroa et al., 1963; Weir, 1964) and suggested important roles for diffusely organized regions such as the reticular formations of the pons, mesencephalon, and thalamus. Specific areas of the subcortex have also been associated with seizure mechanisms, including the hypothalamus (Murphy and Gellhorn, 1945; Jasper and Droogleever-Fortuyn, 1946; Green and

\footnotetext{
Received Jan. 13, 1986; revised Aug. 28, 1986; accepted Sept. 4, 1986.

Supported in part by NIH Grants NS 14834 and GM 07200 and the Seay Neuropharmacology Research Fellowship.

Correspondence should be addressed to Dr. J. A. Ferrendelli, Washington University School of Medicine, 660 South Euclid Avenue, Box 8111, St. Louis, MO 63110 .

Copyright (C) 1987 Society for Neuroscience $0270-6474 / 87 / 030662-09 \$ 02.00 / 0$
}

Morin, 1953; Gellhorn et al., 1959), fields of Forel (Jinnai, 1966; Jinnai et al., 1969; Jinnai and Mukawa, 1970), substantia nigra (Iadarola and Gale, 1982; Garant and Gale, 1983; Gonzalez and Hettinger, 1984; McNamara et al., 1983, 1984), and several thalamic nuclei (Mullen et al., 1967; Jinnai et al., 1969; Feeney and Gullotta, 1972; Kusske et al., 1972; Van Straaten, 1975; Quesney et al., 1977).

Recently we observed the selective metabolic activation of the mammillary bodies (MB) and their immediate connections during a threshold convulsive stimulus induced by the co-infusion of pentylenetetrazol (PTZ) and ethosuximide (ESM) (Mirski and Ferrendelli, 1983). We also reported preliminary data demonstrating that the interruption of the mammillothalamic tracts (MT), bilaterally, had a substantial protective effect against the convulsant PTZ (Mirski and Ferrendelli, 1984a, b). In the present report we examined in detail the effects of interruption of both afferent and efferent connections of the $\mathrm{MB}$ on PTZ-induced seizures.

\section{Materials and Methods}

Lesions. Lesions were directed towards the interruption of the major connections of the MB and of destruction of the nuclear complex itself. However, apparently because of its ventral location at the base of the brain, large lesions required to ablate the MB were accompanied by a high incidence of severe brain hemorrhage, resulting in substantial animal morbidity and mortality. In light of these effects, direct MB ablation was not pursued.

Female albino guinea pigs (250-300 gm, Isaacs), anesthetized with a $4 \%$ halothane (Fluothane, Ayerst) in $\mathrm{O}_{2}$, were placed in a rat stereotaxic frame (Kopf) equipped with a guinea pig adapter. Electrolytic lesioning was performed using a stainless steel electrode, $250 \mu \mathrm{m}$ diameter with a $100 \mu \mathrm{m}$ exposed tip, attached to a DC constant-current lesion maker (Grass). Current ranged from 0.5 to $1.5 \mathrm{~mA}$ with a pulse time of 5-30 sec. Following surgery, the scalp was sutured, and the animals were allowed to recover 1 week prior to testing. Mortality from the operative procedure was $<5 \%$, and no abnormal behavior was noted following the surgery in most animals. Animals that experienced substantial motor impairment or feeding abnormality accompanied by weight loss were discarded from the study $(<5 \%)$. Lesion coordinates with the incisor bar set at -10.0 were the following: Fornix, $1.6 \mathrm{~mm}$ posterior to Bregma (AP), $1.2 \mathrm{~mm}$ lateral to the superior sagittal suture (L), and $9.0 \mathrm{~mm}$ ventral to cortical surface $(\mathrm{H})$; Mammillothalamic tracts, $2.6 \mathrm{~mm} \mathrm{AP}$, $1.2 \mathrm{~mm} \mathrm{~L}$, and $8.2 \mathrm{~mm} \mathrm{H}$; Mammillary peduncles, $4.7 \mathrm{~mm} \mathrm{AP,} 1.0$ $\mathrm{mm} \mathrm{L}$, and $10.7 \mathrm{~mm} \mathrm{H}$.

Behavioral testing. Experiments on mortality and behavior after administration of PTZ wcre performcd using intrapcritoncal injections of the convulsant $(50 \mathrm{mg} / \mathrm{ml})$ dissolved in saline. Clinical behavior following PTZ was observed and scored as follows: 0 , no seizure; 1 , mild clonic; 2, severe clonic (explosive motor activity); 3, severe clonic within the first $10 \mathrm{~min} ; 4$, severe recurrent clonics; 5 , steady clonic with the animal on its side; 6 , same as 5 but within the first $10 \mathrm{~min}$. Animals tested more than once with PTZ were allowed a 4-5 d recovery period between challenges with the convulsant. 
Electroencephalographic (EEG) recording. Animals were lightly anesthetized with halothane, tracheotomized, and paralyzed with $50 \mathrm{mg} / \mathrm{kg}$ Flaxedil (gallamine triethiodide, Davis \& Geck). A $1 \%$ solution of procainc $\mathrm{HCl}$ (Novocain, Breon) was immediately applied to all wound margins, and the animals were ventilated with a $\mathrm{N}_{2} \mathrm{O} / \mathrm{O}_{2}$ mixture, the ratio of which was adjusted around $65 \% / 35 \%$ to keep the arterial $\mathrm{PO}_{2}$ above $100 \mathrm{mg} \mathrm{Hg}$. The arterial $\mathrm{PCO}_{2}$ was kept at approximately $35 \mathrm{~mm}$ $\mathrm{Hg}$ by adjustment of the ventilation rate. The arterial $\mathrm{pH}$ was thus kept approximately $7.40 \pm 0.05$. The body temperature was maintained at $37.0 \pm 0.5^{\circ} \mathrm{C}$ by a heating apparatus. A femoral artery was cannulated for blood pressure and blood gas monitoring. The skull was exposed and 4 stainless steel electrodes were placed in the parietal bones, 2 on each side of the sagittal suture, approximately $2 \mathrm{~mm}$ lateral to it and 6 $\mathrm{mm}$ apart from the ipsilateral electrode.

The blood pressure was continuously monitored, and the animal was rejected if it fell significantly below normal $(76 / 48 \mathrm{~mm} \mathrm{Hg})$. The EEG was recorded on a Grass model 7D polygraph.

The EEG was recorded for $1 \mathrm{hr}$ after the injection of PTZ, and the expression of repetitive high-voltage synchrony was quantified. After being tested, the animals were sacrificed and their brains fixed in $10 \%$ formalin, imbedded in paraffin, sectioned, and stained for histological examination. Locating the lesions was done without knowledge of the previous response of the animal to PTZ.

\section{Results}

\section{Control animals}

Examination of control, unlesioned animals treated with PTZ revealed that the threshold for clonic seizure activity was $\mathbf{5 0}$ $\mathrm{mg} / \mathrm{kg}$, and this dosage resulted in no fatalities. Both 75 and $100 \mathrm{mg} / \mathrm{kg}$ PTZ induced severe clinical seizures, beginning approximately 90 and $45 \mathrm{sec}$, respectively, following injection. The onset of the convulsions was characterized by repetitive myoclonic jerks, forepaw retraction, and torsion of the head. This relatively minor seizure activity was followed by explosive uncontrollable running and/or recurrent clonic seizures. Tonic seizures occurred in many animals, but classic full tonic extension of hindlimb or forelimb was rarely observed. Tabulated mean seizure scores for the control animals approached the maximum possible of 6 at $75 \mathrm{mg} / \mathrm{kg}$ PTZ, and all controls had a maximum score at $100 \mathrm{mg} / \mathrm{kg}$ (Fig. 1A). A dose of $75 \mathrm{mg} / \mathrm{kg}$ of the convulsant was lethal in $81 \%\left(\mathrm{LD}_{81}\right)$ of the animals, and $100 \mathrm{mg} /$ $\mathrm{kg}$ was lethal in $100 \%\left(\mathrm{LD}_{100}\right)$ (Fig. $1 B$ ).

Control guinea pigs were also examined electroencephalographically, under paralyzed and ventilated conditions, to monitor the effects of PTZ on cortical electrical activity. Because $100 \mathrm{mg} / \mathrm{kg}$ of the convulsant resulted in variable EEG responses in control animals, $150 \mathrm{mg} / \mathrm{kg}$, a supermaximal dose, was administered in this study. This dose in control animals reliably produced repetitive hypersynchronous seizure discharges on EEG that occupied slightly more than $50 \%$ of the recording time (Fig. $1 C$ ).

\section{Mammillothalamic tract (MT) lesions}

Guinea pigs with lesions in the mid-diencephalon, roughly that portion traversed by the MT, were challenged with injections of PTZ. A total of 83 bilaterally lesioned animals were examined, as well as 10 animals with unilateral lesions. The response to administration of $50 \mathrm{mg} / \mathrm{kg}$ PTZ in all lesioned guinea pigs was similar to the observed effects in control animals; i.e., no convulsions or only minor clonic activity. The injection of 75 $\mathrm{mg} / \mathrm{kg}$ to the mid-diencephalic lesioned animals resulted in a broad spectrum of seizure severity. Of the 83 bilaterally lesioned animals tested at $75 \mathrm{mg} / \mathrm{kg} \mathrm{PTZ}, 28(33.7 \%)$ had no severe clonic activity (seizure score of 0 or 1 ) as compared to 6 of $114(5.3 \%)$ control animals tested at that dose. This data is reflected in the mean seizure score (Fig. $1 A$ ). The mortality rate at $75 \mathrm{mg} / \mathrm{kg}$
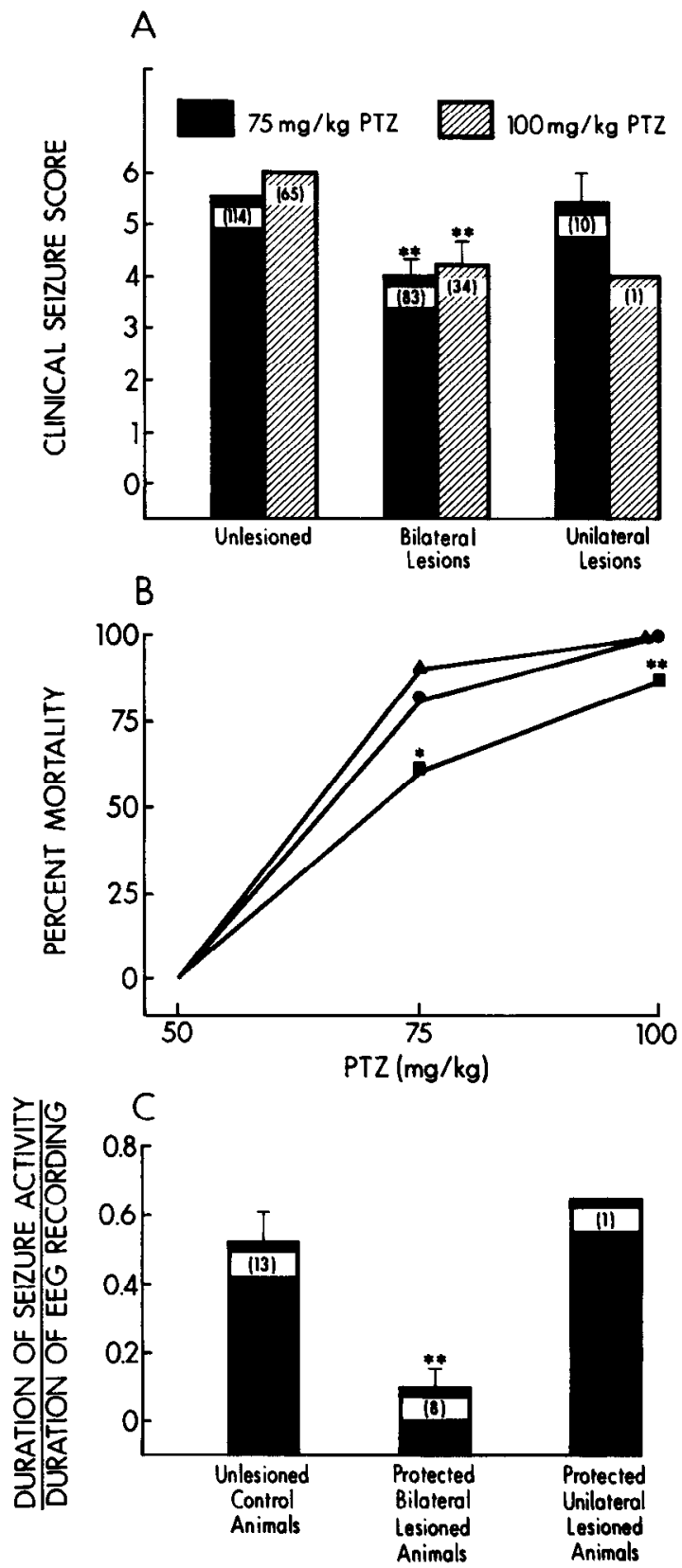

Figure 1. Comparison of the effects of PTZ in control guinea pigs, unlesioned animals, and those with unilateral or bilateral mid-diencephalon lesions. $A$, Effects of 75 and $100 \mathrm{mg} / \mathrm{kg}$ PTZ on behavior. Clinical seizures were scored as follows: 0 , no seizure; 1 , mild clonic; 2 , severe clonic (explosive motor activity); 3 , severe clonic within first $10 \mathrm{~min}$; 4 , severe recurrent clonics; 5 , steady clonic with animal on its side; 6 , same as 5 but within first $10 \mathrm{~min}$. Number of animals per group in parentheses. B, Effects of i.p. PTZ on mortality rate in control and lesioned guinea pigs: $\boldsymbol{Q}$, control animals; $\boldsymbol{\Omega}$, bilaterally lesioned animals; $\Delta$, unilaterally lesioned animals. $C$, EEG effects of $150 \mathrm{mg} / \mathrm{kg}$, i.p. PTZ in paralyzed and ventilated control and lesioned guinea pigs. Recording time period of $1 \mathrm{hr}$ began immediately following injection of the convulsant. ${ }^{*} p<0.005 ;{ }^{* *} p<0.001$.

PTZ in the lesioned group was $60.2 \%$, a decrease of $26 \%$ from that of controls. The animals that survived treatment with 75 $\mathrm{mg} / \mathrm{kg}$ PTZ ( $n=34$ ) were then challenged with $100 \mathrm{mg} / \mathrm{kg}$, the $\mathrm{LD}_{100}$ dose in controls. Of these, 11 (13.3\% of total) survived. In addition, none of these survivors exhibited severe seizure activity, resulting in the significant difference in clinical seizure 

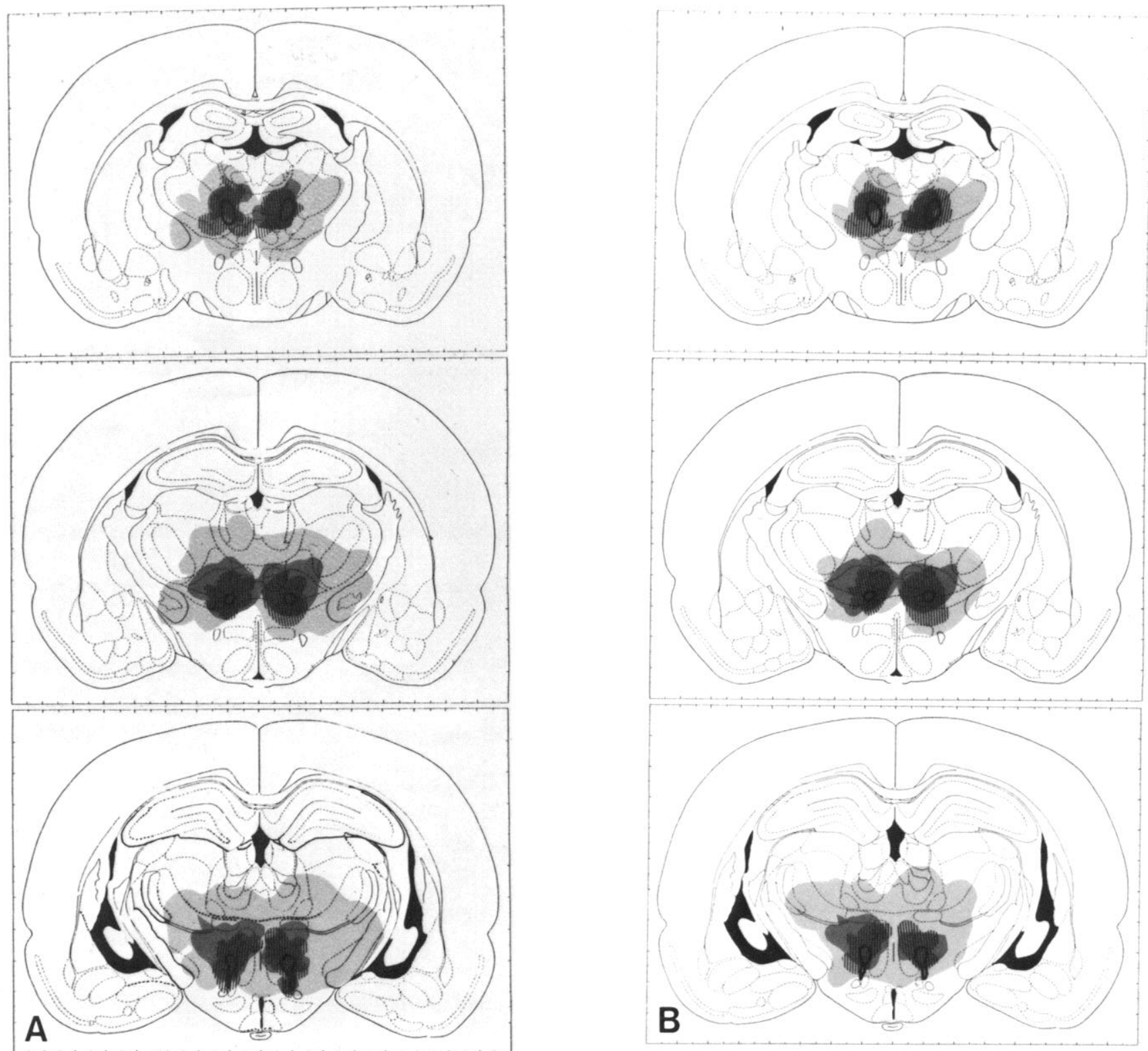

Figure 2. Coronal brain sections of mid-diencephalon from anterior (top) to posterior (bottom) with composites of bilateral mid-diencephalic lesions from guinea pigs: not surviving $75 \mathrm{mg} / \mathrm{kg}$ PTZ challenge (light gray); surviving $75 \mathrm{mg} / \mathrm{kg}$ PTZ without seizures but failing to survive 100 $\mathrm{mg} / \mathrm{kg}$ of the convulsant (dark gray); and surviving both 75 and $100 \mathrm{mg} / \mathrm{kg} \mathrm{PTZ}$ without behavioral seizures (hatched area). The MT is outlined

scores at $100 \mathrm{mg} / \mathrm{kg}$ PTZ between control $(6.0 \pm 0.0)$ and the lesioned group $(4.2 \pm 0.5)$. There was no significant protective effect observed in the unilaterally lesioned animals. Of the 10 animals tested, 9 died following $75 \mathrm{mg} / \mathrm{kg}$ PTZ. The surviving guinea pig also survived $100 \mathrm{mg} / \mathrm{kg}$ but had severe clonic seizures.

Mid-diencephalic lesioned guinea pigs that survived both 75 and $100 \mathrm{mg} / \mathrm{kg}$ PTZ challenges without severe behavioral seizure activity were examined by EEG following $150 \mathrm{mg} / \mathrm{kg}$ of the convulsant. Eight animals were tested in this manner, and of these, 3 experienced no hypersynchronous activity, the range for the remaining 5 was between 2 and $47 \%$ of the recording period. The mean for the 8 animals was $9.4 \%$, a decrease of $82 \%$ from control. The single unilaterally lesioned survivor was also examined by EEG and hypersynchronous activity accounted for $65 \%$ of the recording time (Fig. $1 C$ ).
In an effort to correlate the observed protective effect of the lesions with the neuroanatomical structures destroyed in the electrolytic process, composites of histologically determined lesion volumes were constructed. Figure $2 A$ is a set of composites of (1) all mid-diencephalic lesions; (2) lesions of animals protected at $75 \mathrm{mg} / \mathrm{kg}$ PTZ (seizure score of 0 or 1) but not at 100 $\mathrm{mg} / \mathrm{kg}$; and (3) lesions of animals protected both at 75 and 100 $\mathrm{mg} / \mathrm{kg}$ PTZ. Individual lesion size varied from 0.5 to $3.0 \mathrm{~mm}$ in diameter. The structures principally affected anteriorly by the lesions were the thalamus and subthalamic area. More posteriorly, the hypothalamus was increasingly incorporated into the ablated region, as were the posterior thalamus, subthalamus, and internal capsule.

Comparison of the composite volumes of lesions revealed that the portion of the diencephalon destroyed in animals protected against $75 \mathrm{mg} / \mathrm{kg}$ PTZ was smaller than that of the com- 

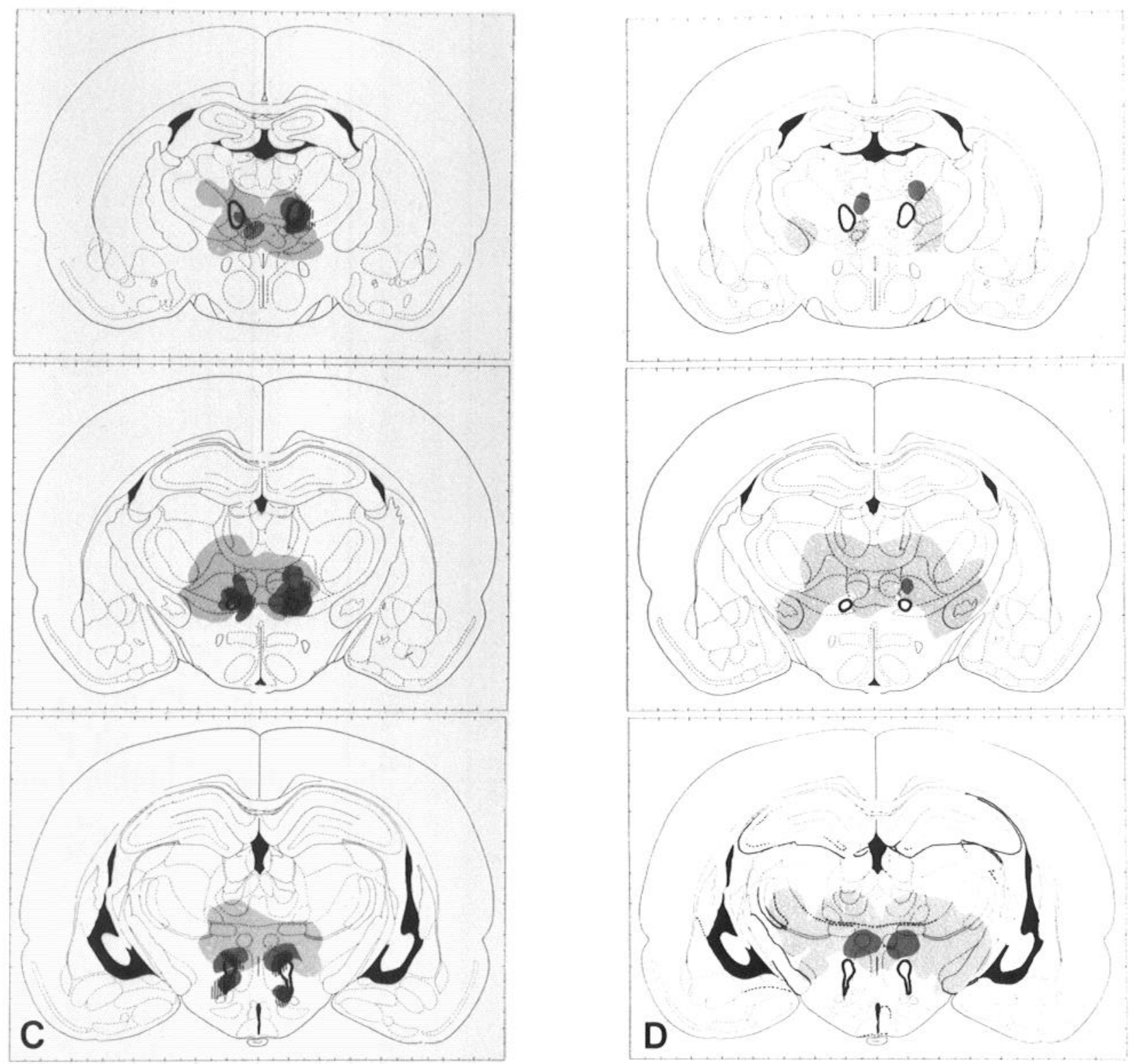

in black. $A$, All animals with mid-diencephalic lesions. $B$, All animals with lesions transecting the MT. $C$, All animals with lesions partially interrupting the MT. $D$, All animals with lesions not affecting the MT.

posite of all lesioned brain volumes. The composite volume of protective lesions was still further reduced when only lesions of guinea pigs protected from severe seizures at both 75 and 100 $\mathrm{mg} / \mathrm{kg}$ PTZ were considered. Structures incorporated within this boundary included only portions of both anterior and ventral thalamus, the subthalamic region including the MT, and dorsal parts of the hypothalamus (Fig. 2A). Lesions in this group ranged from $0.5 \mathrm{~mm}$ to no more than $1.5 \mathrm{~mm}$ in diameter.

A retrospective analysis was also performed examining the effects of interruption of the MT on PTZ-induced seizures. Lesions were accordingly divided into 3 groups: (1) complete bilateral interruption of the MT $(n=38) ;(2)$ partial interruption of the MT, bilaterally or unilaterally $(n=21)$; and (3) no interruption of the tracts bilaterally $(n=24)$. Both mortality and clinical seizure score were assessed in each group (Fig. 3).

Animals with lesions not involving the MT did not differ from controls with respect to either mortality or behavioral seizure activity. No lesions avoiding the MT resulted in protection at $100 \mathrm{mg} / \mathrm{kg}$, and only 2 prevented seizures at $75 \mathrm{mg} /$ $\mathrm{kg}$ PTZ. Analyzed as a group, all lesions completely interrupting the MT bilaterally were very protective, decreasing the seizure score by $38 \%$ at $75 \mathrm{mg} / \mathrm{kg}$ and $33 \%$ at $100 \mathrm{mg} / \mathrm{kg}$ PTZ; however, the degree of protection was dependent on lesion size (see below). A parallel reduction in mortality was also noted: 20 of 38 (53\%) MT lesioned animals survived $75 \mathrm{mg} / \mathrm{kg}$ PTZ (compared with $19 \%$ in controls) and 7 of $38(18 \%)$ survived the control $\mathrm{LD}_{100}$ dose. Of the 8 animals analyzed by EEG, 5 had complete MT lesions and 3 had partial lesions. EEG seizure activity in each subgroup was significantly reduced from control (Fig. 3C).

Of interest in this study, bilateral lesions resulting in partial MT interruption were as protective as those completely interrupting the tracts. Unilaterally lesioned animals, however, were not protected regardless of the type of lesion. Of the 10 guinea pigs with unilateral lesions, 3 were complete MT lesions, 4 were 

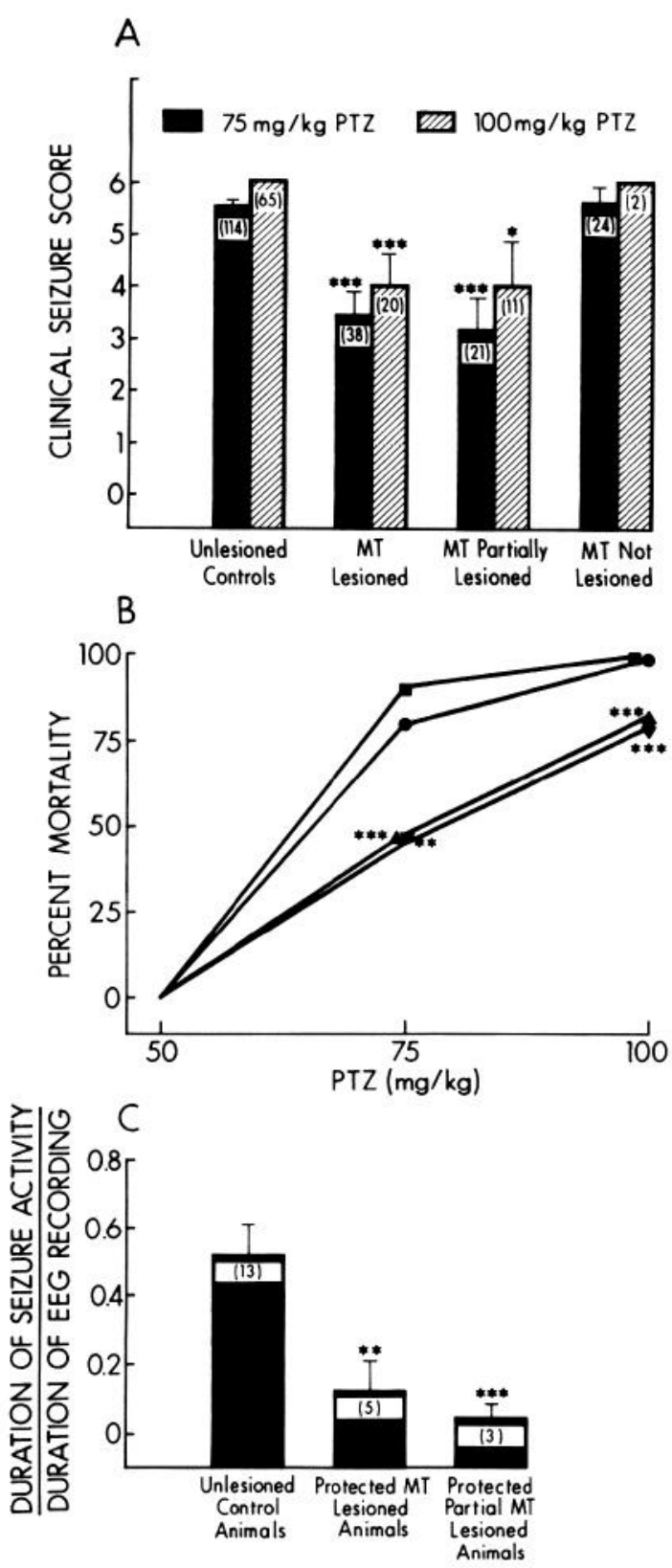

Figure 3. Comparison of the effects of PTZ in control, unlesioned guinea pigs, and animals with bilateral MT lesions, partial MT lesions, and lesions not interrupting the MT. $A$, Effects of 75 and $100 \mathrm{mg} / \mathrm{kg}$, i.p., PTZ on behavior in control and lesioned guinea pigs. (See Figure 1 or Materials and Methods for description of scoring system.) $B$, Effects of i.p. PTZ on mortality rate in control and lesioned guinea pigs: $\bullet$, control animals; $\boldsymbol{\nabla}$, MT-lesioned animals; $\boldsymbol{\Lambda}$, partial MT-lesioned animals; $\mathbf{n}$, animals with lesions not affecting the MT. $C$, EEG effects of $150 \mathrm{mg} / \mathrm{kg}$, i.p., PTZ in paralyzed and ventilated control, bilateral MT, and partial MT lesioned animals. Recording time period of $1 \mathrm{hr}$ began immediately following injection of the convulsant. ${ }^{*} p<0.05,{ }^{* *} p<$ $0.01,{ }^{* * *} p<0.001$.

partial MT lesions, and the remaining 3 were complete misses. The survivor of 75 and $100 \mathrm{mg} / \mathrm{kg} \mathrm{PTZ} \mathrm{(seizure} \mathrm{score} \mathrm{of} 0$ and 4 , respectively) had a partial MT lesion.

Composites of the complete and partial MT lesion groups, as well as lesions that did not affect the MTs, were also constructed and analyzed by dividing the lesions according to their degree of protection against 75 or 75 and $100 \mathrm{mg} / \mathrm{kg}$ of the convulsant

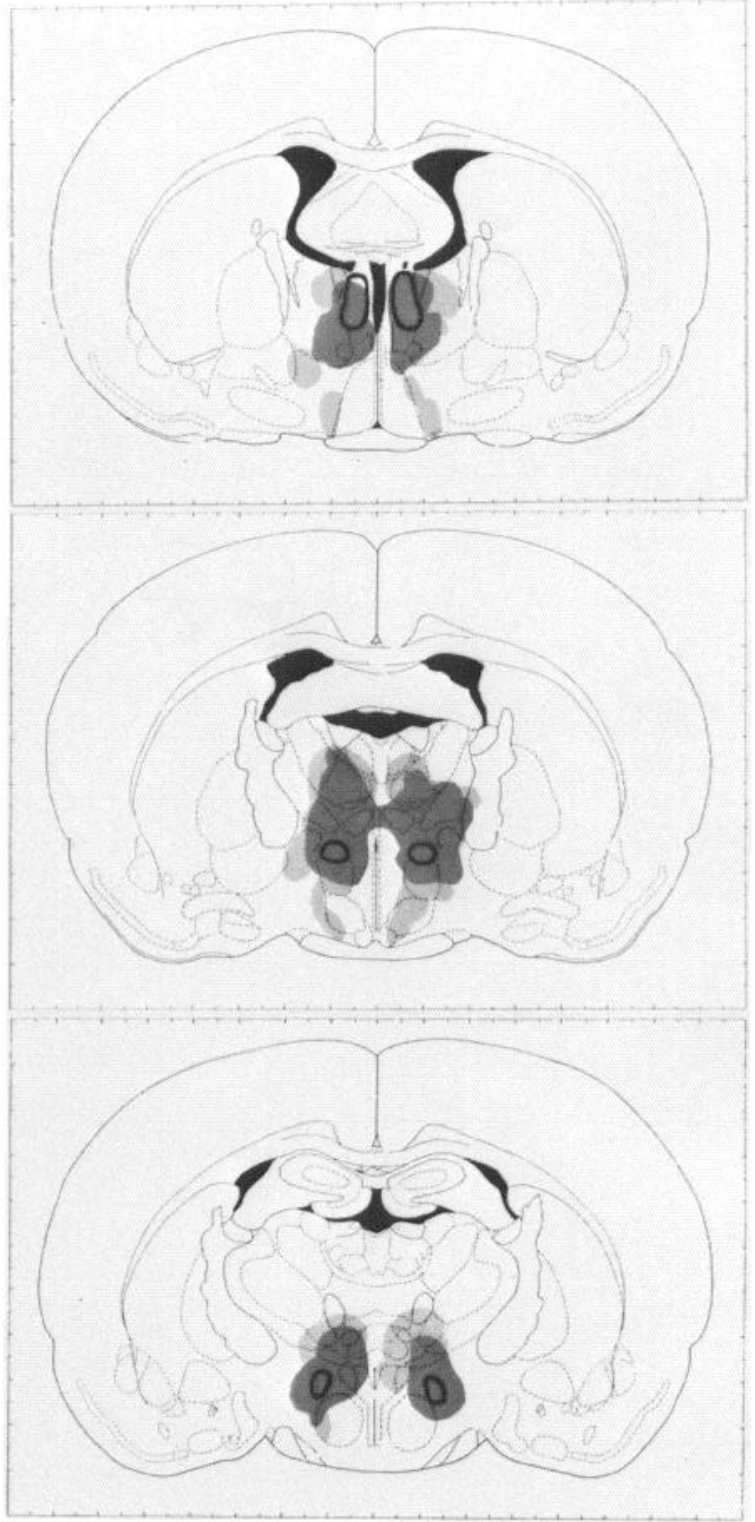

Figure 4. Composite volume analysis of bilateral lesions in guinea pigs transecting or not transecting the post-commissural FX. Coronal atlas sections from anterior (top) to posterior (bottom) of the anterior diencephalon trace the course of the FX (outlined in black). Composite of non-FX lesions, light gray; composite of FX lesions, dark gray.

(Fig. 2, $C, D$ ). It was readily apparent from this analysis that there was an inverse correlation between lesion size and protective effect, i.e., the more protective the lesion, the smaller the size of the ablated area (Fig. $2 B$ ). The smallest lesions, 0.5$1 \mathrm{~mm}$, which were essentially limited to the immediate area adjacent to and including the MT, completely protected against the convulsant and lethal effects of PTZ. Slightly larger lesions, $1.0-1.5 \mathrm{~mm}$, were partially protective, and the largest, $>1.5$ $\mathrm{mm}$, were not protective. A similar correlation was noted in the partial MT lesions, the most protective of which were very small and adjacent to the MT (Fig. 2C). Lesions in animals that survived $75 \mathrm{mg} / \mathrm{kg}$ PTZ with no clinical seizures and without complete or partial interruption of the MT $(n=2)$ were found to be very small and just dorsal to the 2 tracts (Fig. $2 D$ ). 


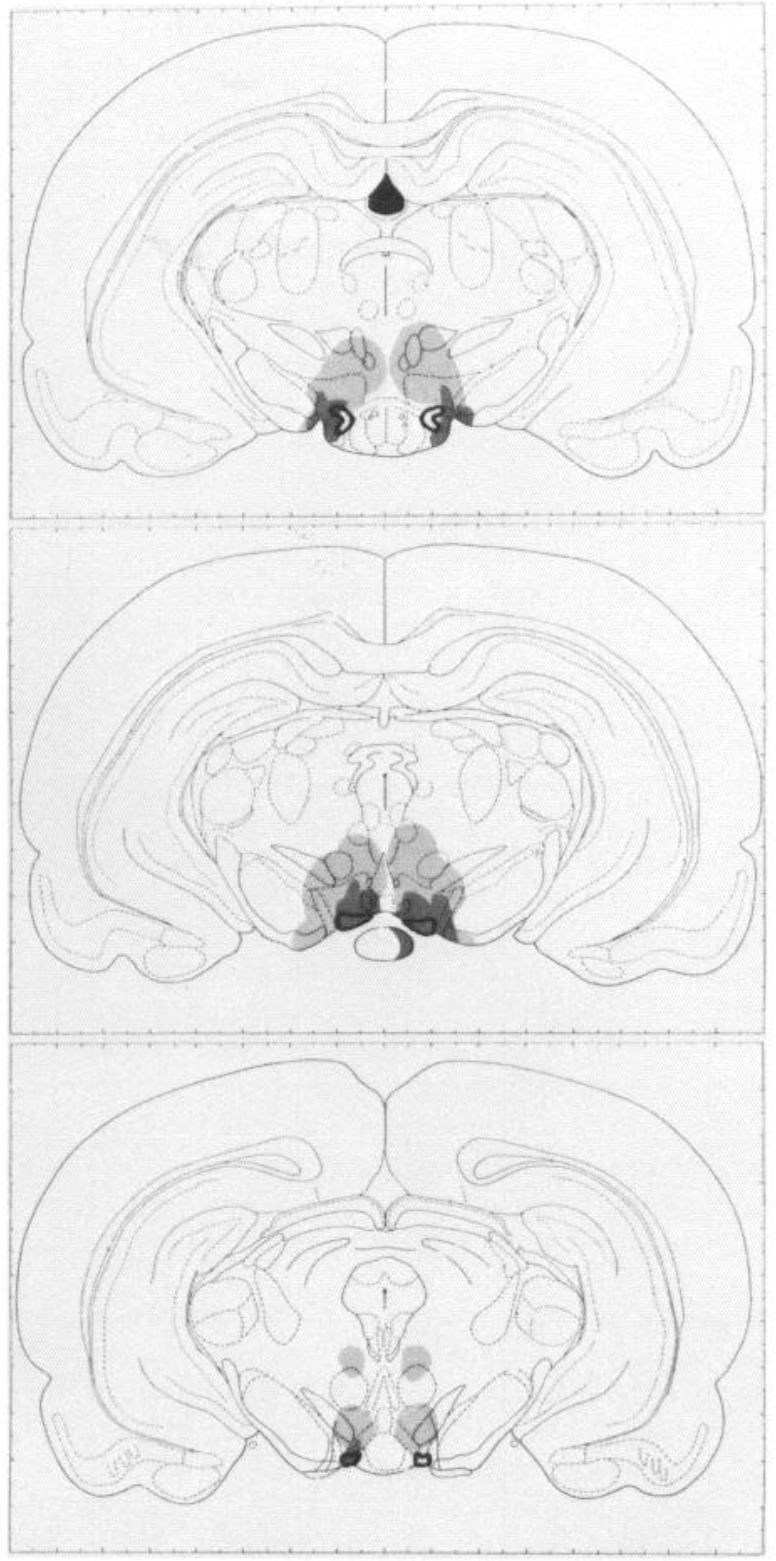

Figure 5. Composite volume analysis of bilateral lesions in guinea pigs transecting or not transecting the MP. Coronal atlas sections from anterior (top) to posterior (bottom) of the posterior diencephalon trace the course of the MP (outlined in black). Composite of non-MP lesions, light gray; composite of MP lesions, dark gray.

\section{Fornix $(F X)$ and mammillary peduncle $(M P)$ lesions}

Bilateral electrolytic lesions in the anterior diencephalon or midbrain were produced in an effort to interrupt the FX and MP, respectively. The anterior diencephalon of 17 animals was examined, 10 having histologically confirmed bilateral FX lesions and 7 having a lesion not affecting the tract. For the midbrain, the experimental group consisted of 26 animals equally divided between those with MP lesions and those with non-MP lesions. Composite volumes for each of the FX and MP groups were constructed (Figs. 4 and 5). Animals with bilateral interruption of the tracts were compared with those without tract lesions and also with unlesioned controls following 75 and $100 \mathrm{mg} / \mathrm{kg}$ PTZ.

Injection of $75 \mathrm{mg} / \mathrm{kg}$ of the convulsant resulted in a mean
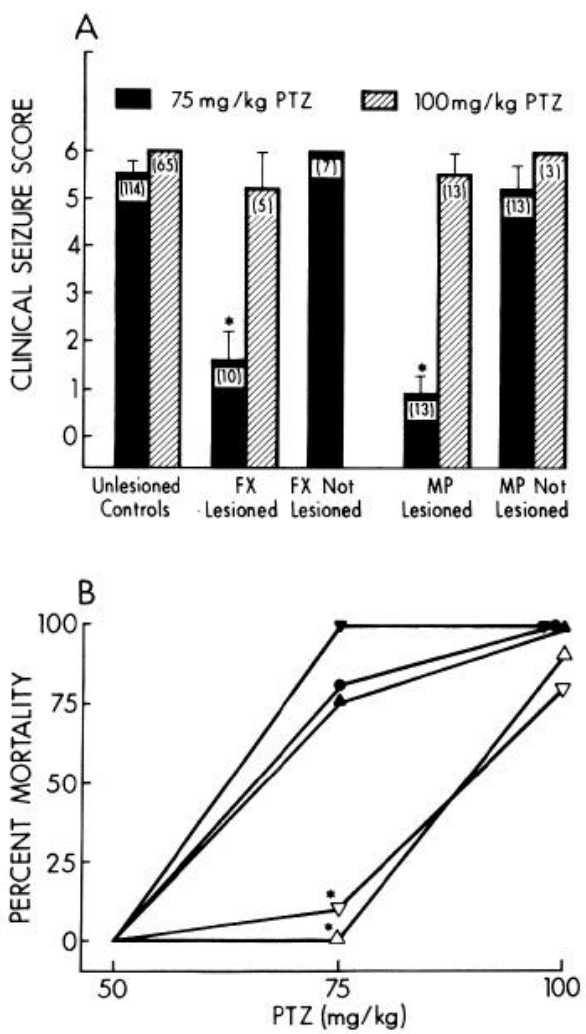

Figure 6. Behavioral and lethal effects of PTZ in control, unlesioned guinea pigs and animals with bilateral lesions of the FX or MP. A, Effects of 75 and $100 \mathrm{mg} / \mathrm{kg}$, i.p., PTZ on clinical seizure activity. See Figure 1 or Materials and Methods for description of scoring system. $B$, Effects of i.p. PTZ on mortality rate in control and lesioned guinea pigs. Symbols: $\bullet$, control animals; $\boldsymbol{\nabla}$, animals with lesions near but not interrupting the FX; $\nabla$, animals with lesions of the FX; $\boldsymbol{\Lambda}$, animals with lesions near, but not interrupting, the MP; $\triangle$, animals with lesions of the MP. ${ }^{*} p<0.001$.

seizure score of $1.6 \pm 0.6$ and $0.9 \pm 0.3$ in the FX and MP lesioned guinea pigs, respectively (Fig. 6A). These significantly attenuated responses were specific for lesions interrupting the tracts. At this dose, lesions of either pathway resulted in a significant concomitant reduction in mortality, from an $\mathrm{LD}_{81}$ to an $\mathrm{LD}_{10}$ (FX) and $\mathrm{LD}_{0}$ (MP) (Fig. 6B).

At $100 \mathrm{mg} / \mathrm{kg}$ PTZ, however, no significant protective effect was observed. Only 1 of 5 FX-lesioned and 1 of 13 MP-lesioned animals tested at that dose survived. In contrast to the MTlesioned animals, several FX-lesioned guinea pigs completely protected from behavioral seizure activity at $75 \mathrm{mg} / \mathrm{kg}$ PTZ were not tested at $100 \mathrm{mg} / \mathrm{kg}$ but were examined electroencephalographically with injection of $150 \mathrm{mg} / \mathrm{kg}$ of the convulsant. The 3 animals tested in this manner experienced repetitive hypersynchronous cortical discharges for a mean of $2.1 \pm 1.8 \%$ of the recording period, as compared with the control value of $51.8 \pm$ $8.3 \%$.

\section{Discussion}

The results of this study demonstrate that lesions in the diencephalon and ventral midbrain may be highly protective against the convulsant action of PTZ. Selected lesions not only blocked the clinical convulsant activity and lethal effect of the drug but also prevented electrical seizure discharges. However, results clearly indicate that both the size and the location of the brain 
lesions are important determinants of the anticonvulsant effect.

In our composite volume analysis we observed that discrete lesions in the mid-diencephalon damaging the MT were the most protective. Previous observations in our laboratory using ${ }^{14} \mathrm{C}$-2-deoxyglucose autoradiography had implicated the MT in seizure mechanisms (Mirski and Ferrendelli, 1983). We are therefore of the opinion that interruption of this connection between the mammillary bodies and anterior thalamus is a major factor in the observed anticonvulsant effect. In support of this hypothesis are the facts that no lesion that completely missed the MT was protective at $100 \mathrm{mg} / \mathrm{kg}$ PTZ and that all protective partial MT lesions visibly destroyed only small regions of adjacent brain tissue. Of course we cannot fully exclude the possibility that nearby structures such as the subthalamic region or ventral thalamus have a role in the protective effect of the lesions.

Lesions involving the FX or MP were similarly demonstrated to result in a significant increase in threshold to the convulsant PTZ. By comparing lesioned and non-lesioned FX or MP composite volumes, the association between the protective effect of the lesions and the interruption of the 2 major afferents to the MB was strengthened. That both afferent and efferent MB pathways have a facilitatory influence on PTZ seizures strongly supports the concept that this hypothalamic nucleus has an important role in the expression of generalized seizures.

Most neurons in the medial mammillary bodies have bipolar axons that send processes rostrally to the anterior nucleus of the thalamus via the MT and caudally to the dorsal and ventral tegmental nuclei of the brain stem via the mammillotegmental tract (Cowan et al., 1964; Cruce, 1975, 1977; Van der Kooy et al., 1978; Veazey et al., 1982a, b). Rcciprocal connections from the tegmental nuclei to the MB project anteriorly in the MP. This pathway between the upper brain stem and the anterior thalamus was first referred to by Nauta as the "thalamic-midbrain circuit" (Nauta, 1958). Our previous observation of selective metabolic activation of this circuit by a threshold convulsant stimulus was the first indication that it is involved in the expression of generalized seizures. That interruption of the MT or MP prevents PTZ seizures indeed suggests that this system may, in part, mediate the convulsive action of PTZ between the thalamus and brain stem.

The involvement of the $\mathrm{MB}$ and its connections in seizure mechanisms is supported by several lesion studies by other investigators. The anterior thalamus, for example, has been associated with the expression of both focal and generalized convulsant activity. Kusske et al. (1972) reported that lesions of ventral anterior thalamus decreased seizure frequency and duration in experimental models of focal cortical epilepsy, thereby preventing the generalization of the seizures. Similarly, Feeney and Gullotta (1972) demonstrated marked suppression of seizure discharges by lesions of the rostral thalamus. Marked depression of the responsiveness of centrum medianum cells was observed following rostral thalamic lesion, suggesting that the rostral thalamus may exert tonic control over other thalamic nuclei (Feeney et al., 1970). Stereotaxic lesion of anterior thalamus has also been clinically successful in the treatment of partial and generalized epilepsy (Spiegel et al., 1951; Mullen et al., 1967).

Jinnai and colleagues, experimenting on cats, observed a significant increase in the threshold to PTZ following subcortical lesions, particularly in the mesencephalic reticular formation and the posterior, but not anterior, hypothalamus (Jinnai et al.,
1969). In that study, bilateral lesions in the MB resulted in an almost 2-fold increase in PTZ seizure threshold. Inadvertent interruption of the MT has also been described in several case studies of epileptic patients successfully treated surgically (Mullen et al., 1967). Finally, fornicotomies have been reported to be effective in the alleviation of several varieties of seizures in humans, including generalized epilepsy (Orthner and Lohman, 1966; Schaltenbrand et al., 1966).

It was observed during the composite analysis of lesions in the mid-diencephalon that the most protective lesions were those that damaged the MT and only very small portions of adjacent brain tissue. Indeed, large lesions involving the MT were not protective. Although seemingly paradoxical, this observation can be understood in light of the accumulated evidence demonstrating both facilitatory and inhibitory influences in the diencephalon on the expression of seizures (Andy and Mukawa, 1959; Gellhorn et al., 1959; Milhorat et al., 1966; Jinnai et al., 1969; Gloor et al., 1977; Quesney et al., 1977). The failure of such large ablations to attenuate the PTZ convulsions suggests that destruction of other neuronal structures near the MT has an opposite, facilitatory effect on the expression of generalized seizures. This observation that large and small diencephalic lesions incorporating the same regions of brain may have opposite effects on seizure theshold has, in fact, been previously reported (Milhorat et al., 1966; Mullen et al., 1967). In our middiencephalic lesion experiments, the volume difference between the composite of all MT lesions and of the most protective MT lesions yields a region of brain that may be presumed to include a powerful inhibitory influence on seizure expression. Within this volume are several structures-such as the thalamic ventrolateral and centromedian nuclei, anterior hypothalamus, and dorsorostral midbrain - that have been previously associated with inhibition of paroxysmal activity (Milhorat et al., 1966; Jinnai et al., 1969). The severe limitation on the extent of the damaged area was not apparent in the FX lesions. Both small and large lesions in the anterior diencephalon interrupting the FX resulted in similar anticonvulsant effects. No correlation can be drawn from the MP lesion data either, as the ablated brain areas in these cases were all very discrete.

The anticonvulsant effect of FX and MP interruption suggests that neuronal activity between the hippocampus, brain stem, and $\mathrm{MB}$ also facilitates the expression of generalized seizures. Thus, the MB may serve to mediate convulsant activity between hippocampus, brain stem, and thalamus. This concept is supported by the observations of Green and Morin (1953). Upon stimulation of various diencephalic structures, they reported the elicitation of "seizure-like activity" in the cerebral cortex only after stimulation in the diencephalon of the posterior hypothalamus, FX, MT, or anterior thalamus. Furthermore, the protective effect observed in the present study with bilateral MT lesions, as well as with lesions to either the FX or MP, suggests that the MT may be the final common pathway of propagation of paroxysmal activity to the thalamus and cortex from MBassociated subcortical structures.

Although the mechanisms involved in the initiation and propagation of generalized seizures is not entirely clear, experimental evidence supports the concept of an interactive process between cortical and subcortical influences in the generation of these attacks (Gloor, 1968; Gloor et al., 1977; Quesney et al., 1977). It has been argued that cortical mechanisms, clearly important in the final expression of cortical seizure discharges and consequent evoked behavioral manifestations, may also have the 
primary role in eliciting generalized attacks (Ingvar, 1959; Bancaud, 1971; Goldring, 1972; Mutani et al., 1973; Bancaud et al., 1974). More recent evidence, however, has emphasized the role of the diencephalon and brain stem in the early events of seizure activity. As previously mentioned, structures such as the thalamic, mesencephalic, and pontine reticular formations, specific thalamic nuclei, hypothalamus and substantia nigra have been shown to mediate in some fashion the expression of various types of generalized seizures.

PTZ is a chemical convulsant that produces generalized seizures and is widely used as an experimental model for human petit mal epilepsy. Although its specific mechanism of action is not known, PTZ has been demonstrated to alter both neuronal membrane and synaptic properties (Eyzaguirre and Lilienthal, 1949; Bignami et al., 1966; DeRobertis et al., 1969; Prichard, 1971; Gross and Woodbury, 1972; Pellmar and Wilson, 1977; Fowler and Partridge, 1984). This convulsant has also been reported to be a selective antagonist of GABA (MacDonald and Barker, 1978). Because human petit mal epilepsy and PTZinduced seizures are both selectively prevented by the anticonvulsant ethosuximide, it has been suggested that the epileptogenic mechanisms at either the cellular or systems level are similar.

Although PTZ exerts its effects throughout the CNS, the evidence suggests that subcortical mechanisms are important in the pathogenesis of generalized seizure produced by this drug. Especially intriguing are the experiments by Faingold (1977, 1978a, b, 1980), Velasco et al. (1975, 1976), and Rodin et al. (1970), which have established that the earliest detectable effects of PTZ on brain activity are found in the mesencephalic and rhombencephalic reticular formations, preceding subscquent evoked activity in other brain regions. The MB and its connections, by forming a thalamic-midbrain pathway, may be an important circuit in the functional anatomy involved in the propagation of PTZ generalized seizures. Possibly, this anatomical pathway may also mediate, in part, the expression of petit mal epilepsy in humans.

\section{References}

Andy, O. J., and J. Mukawa (1959) Brain stem lesion effects on electrically induced seizures (electroencephalographic and behavioral study). Electroencephalogr. Clin. Neurophysiol. 11: 397.

Bancaud, J. (1971) Rôle du cortex cerebral dans les epilepsies "generalisees" d'origine organique. Presse Med. 79: 669-673.

Bancaud, J., J. Talairach, P. Morel, M. Bresson, S. Geier, E. Hemon, and P. Buser (1974) "Generalized" epileptic seizures elicited by electrical stimulation of the frontal lobe in man. Electroencephalogr. Clin. Neurophysiol. 37: 275-282.

Bergman, F., A. Costin, and J. Gutman (1963) A low threshold convulsive area in the rabbit's mesencephalon. Electroencephalogr. Clin. Neurophysiol. 15: 683-690.

Bignami, A., G. Palladini, and G. Venturini (1966) Effect of cardiazol on sodium-potassium-activated adenosine triphosphatase in the rat brain in vivo. Brain Res. $1: 413-414$.

Cowan, W. M., R. W. Guillery, and T. P. S. Powell (1964) The origin of the mammillary peduncle and other hypothalamic connections from the midbrain. J. Anat. (Lond.) 98: 345-363.

Cruce, J. A. F. (1975) An autoradiographic study of the projections of the mammillothalamic tract in the rat. Brain Res. 85: 211-219.

Cruce, J. A. F. (1977) An autoradiographic study of the descending connections of the mammillary nuclei of the rat. J. Comp. Neurol. 176: 631-644.

DeRobertis, E., M. Alberici, and G. R. D. Arnaiz (1969) Astroglial swelling and phosphohydrolases in cerebral cortex of Metrazol convulsant rats. Brain Res. 12: 461-466.

Eyzaguirre, C., and J. L. Lilienthal, Jr. (1949) Veratrinic effects of pentylenetetrazol (Metrazol) and 2,2-bis (p-chlorophenyl) 1,1,1-tri- chloroethane (DDT) on mammalian neuromuscular function. Proc. Soc. Biol. Med. 70: 272-275.

Faingold, C. L. (1977) Convulsant-induced enhancement of non-primary sensory evoked responses in reticular formation pathways. Neuropharmacology 16: 73-81.

Faingold, C. L. (1978a) Brainstem reticular formation mechanisms subserving generalized seizures: Effects of convulsants and anticonvulsants on sensory-evoked responses. Prog. Neuro-Psychopharm. 2: 401-422.

Faingold, C. L. (1978b) Pentylenetetrazol-induced enhancement of responses of mesencephalic reticular neurons to visual stimuli. Brain Res. 150: 418-423.

Faingold, C. L. (1980) Enhancement of mesencephalic reticular neuronal responses to sensory stimuli with pentylenetetrazol. Neuropharmacology 19: 53-62.

Feeney, D. M., and F. P. Gullotta (1972) Suppression of seizure discharges and sleep spindles by lesions of the rostral thalamus. Brain Res. 45: 254-259.

Feeney, D. M., J. D. Schlag, J. Villablanca, and M. Waszak (1970) Depression of the centrum medianum complex response by rostral thalamic lesion. Exp. Neurol. 26: 401-410.

Fowler, J. C., and L. D. Partridge (1984) The effect of pentylenetetrazol on inward currents of non-bursting neurons and its role in plateau formation. Brain Res. 304: 47-58.

Garant, D. S., and K. Gale (1983) Lesions of the substantia nigra protect against experimentally induced seizures. Brain Res. 273: 156161.

Gellhorn, E., A. M. Balling, and M. Kawakami (1959) Studies on experimental convulsions with emphasis on the role of the hypothalamus and the reticular formation. Epilepsia (Amst.) 3: 233-254.

Gloor, P. (1968) Generalized cortico-reticular epilepsies. Some considerations on the pathophysiology of generalized bilaterally synchronous spike and wave discharges. Epilepsia 9:249-263.

Gloor, P., L. F. Fuesney, and H. Zumstein (1977) Pathophysiology of generalized penicillin epilepsy in the cat: The role of cortical and subcortical structures. II. Topical application of penicillin to the cerebral cortex and to subcortical structures. Electroencephalogr. Clin. Neurophysiol. 43: 79-94.

Goldring, S. (1972) The role of prefrontal cortex in GM convulsion. Arch. Neurol. (Chic.) 2: 109-120.

Gonzalez, L. P., and M. K. Hettinger (1984) Intranigral muscimol suppresses ethanol withdrawal seizures. Brain Res. 298: 163-166.

Green, J. D., and F. Morin (1953) Hypothalamic electrical activity and hypothalamo-cortical relationships. Am. J. Physiol. 172: 175186.

Gross, G. J., and D. M. Woodbury (1972) Effects of pentylenetetrazol on ion transport in the isolated toad bladder. J. Pharmacol. Exp. Ther. 181: 257-272.

Guerrero-Figueroa, R., A. Barros, F. de Badbian Verster, and R. G. Heath (1963) Experimental "petit-mal" in kittens. Arch. Neurol. 9: 297-306.

Hunter, J., and H. H. Jasper (1949) Effects of thalamic stimulation in unanesthetized animals. Electroencephalogr. Clin. Neurophysiol. 1 : 305-324.

Iadarola, M. J., and K. Gale (1982) Substantia nigra: Site of anticonvulsant activity mediated by gamma-aminobutyric acid. Science 218 : 1237-1240.

Ingvar, D. H. (1955a) Reproduction of the 3 per second spike and wave EEG pattern by subcortical electrical stimulation in cats. Acta Physiol. Scand. 33: 137-150.

Ingvar, D. H. (1955b) Electrical activity of isolated cortex in the unanesthetized cat with intact brain stem. Acta Physiol. Scand. 33: 151168.

Ingvar, D. H. (1959) On the pathophysiology of the 3 per second spike and wave epilepsy. Electroencephalogr. Clin. Neurophysiol. 11: 187.

Jasper, H. H., and J. Droogleever-Fortuyn (1946) Experimental studies on the functional anatomy of petit mal epilepsy. Res. Publ. Assoc. Res. Nerv. Ment. Dis. 26: 272-298.

Jinnai, D. (1966) Clinical results and the significance of Forel-H-tomy in the treatment of epilepsy. Confin. Neurol. (Basel) 27: 129-136.

Jinnai, D., and J. Mukawa (1970) Forel-H-tomy for the treatment of epilepsy. Confin. Neurol. 32: 307-315.

Jinnai, D., H. Mogami, J. Mukawa, Y. Iwata, and K. Kobayashi (1969) Effects of brain-stem lesions on Metrazol-induced seizures in cats. Electroencephalogr. Clin. Neurophysiol. 27: 404-411. 
Kriendler, A., E. Zuckermann, M. Steriade, and D. Chimion (1958) Electroclinical features of convulsions induced by stimulation of the brain stem. J. Neurophysiol. 21: 430-436.

Kusske, J. A., G. A. Ojemann, and A. A. Ward Jr. (1972) Effects of lesions in ventral anterior thalamus on experimental focal epilepsy. Exp. Neurol. 34: 279-290.

MacDonald, R. L., and J. L. Barker (1978) Specific antagonism of GABA-mediated postsynaptic inhibition of cultured spinal cord neurons: A common mode of convulsant action. Neurology 28: 325-330.

McNamara, J. O., L. C. Rigsbee, and M. T. Galloway (1983) Evidence that substantia nigra is crucial to neural network of kindled seizures. Eur. J. Pharmacol. 86: 485-486.

McNamara, J. O., M. T. Galloway, L. C. Rigsbee, and C. Shin (1984) Evidence implicating substantia nigra in regulation of kindled seizure threshold. J. Neurosci. 4: 2410-2417.

Milhorat, T. H., M. Baldwin, and D. A. Hantman (1966) Experimental epilepsy after rostral reticular formation excision. J. Neurosurg. 24: 595-611.

Mirski, M. A., and J. A. Ferrendelli (1983) Individual and combined effects of convulsant and anticonvulsant drugs on regional brain metabolism. Soc. Neurosci. Abstr. 9: 627.

Mirski, M. A., and J. A. Ferrendelli (1984a) Interruption of the mammillothalamic tracts prevents seizures in guinea pigs. Science 226: 72-74.

Mirski, M. A., and J. A. Ferrendelli (1984b) Interruption of the connections of the mammillary body protects against experimental generalized seizures. Epilepsia 25: 661 .

Morison, R. S., and E. W. Dempsey (1942) A study of thalamocortical relations. Am. J. Physiol. 135: 281-292.

Mullen, S., G. Vailati, J. Karasick, and M. Mailis (1967) Thalamic lesions for the control of epilepsy. Arch. Neurol. 16: 277-285.

Murphy, J. P., and J. Gellhorn (1945) Further investigations on diencephalic-cortical relations and their significance for the problem of emotion. J. Neurophysiol. 8: 431-442.

Mutani, R., L. Bergamini, R. Fariello, and Q. Quatrocolo (1973) Bilateral synchrony of epileptic discharge associated with chronic asymmetrical cortical foci. Electroencephalogr. Clin. Neurophysiol. 34:5359.

Nauta, W. J. H. (1958) Hippocampal projections and related pathways to the midbrain in the cat. Brain $81: 319-340$.

Orthner, H., and R. Lohman (1966) Experience with stereotaxic interventions in epilepsy. Dtsch. Med. Wochenschr. 91: 984-991.

Pellmar, T. C., and W. A. Wilson (1977) Synaptic mechanisms of pentylenetetrazol: Selectivity for chloride conductance. Science 197: 912-914.
Prichard, J. W. (1971) Pentylenetetrazol-induced increase in chloride permeability of leech neurons. Brain Res. 27: 414-417.

Quesney, L. F., P. Gloor, E. Kratzenberg, and H. Zumstein (1977) Pathophysiology of generalized penicillin epilepsy in the cat: The role of cortical and subcortical structures. I. Systemic application of penicillin. Electroencephalogr. Clin. Neurophysiol. 42: 640-655.

Ralston, B., and C. Ajmone-Marsan (1956) Thalamic control of certain normal and abnormal cortical rhythms. Electroencephalogr. Clin. Neurophysiol. 8: 559-582.

Rodin, E. A., T. Okuma, S. Wasson, J. Porzak, and M. Rodin (1970) Neurophysiological mechanisms involved in grand mal seizures induced by Metrazol and Megemide. Electroencephalogr. Clin. Neurophysiol. 30: 62-72.

Schaltenbrand, G., H. Spuler, M. Nadjimi, H. Hopf, and W. Wahren (1966) Die stereotaktische behandlung der epilepsien. Confin. Neurol. 27: 111-113.

Spiegel, E. A., H. T. Wycis, and V. Reyes (1951) Diencephalic mechanisms in petit mal epilepsy. Electroencephalogr. Clin. Neurophysiol. 3: 473-475.

Van der Kooy, D., H. G. J. M. Kuypers, and C. E. Catsman-Berrevoets (1978) Single mammillary body cells with divergent axon collaterals. Demonstration by a simple, fluorescent retrograde double labeling technique in the rat. Brain Res. 158: 189-196.

Van Straaten, J. J. (1975) Abolition of electrically induced cortical seizures by stereotactic thalamic lesions. Neurology 25: 141-149.

Veazey, R. B., D. G. Amaral, and W. M. Cowan (1982a) The morphology and connections of the posterior hypothalamus in cynomolgus monkey (Macaca fascicularis). I. Cytoarchitectonic organization. J. Comp. Neurol. 207: 114-134.

Veazey, R. B., D. G. Amaral, and W. M. Cowan (1982b) The morphology and connections of the posterior hypothalamus in cynomolgus monkey (Macaca fascicularis). II. Efferent connections. J. Comp. Neurol. 207: 135-156.

Velasco, F., M. Velasco, F. Estrada-Villanueva, and J. P. Machado (1975) Specific and nonspecific multiple unit activities during the onset of pentylenetetrazol seizures. I. Intact animals. Epilepsia 16: 207-214.

Velasco, F., M. Velasco, H. Maldonado, and F. Estrada-Villanueva (1976) Specific and nonspecific multiple unit activities during the onset of pentylenetetrazol seizures. II. Acute lesions interrupting nonspecific system connections. Epilepsia 17: 461-475.

Weir, B. (1964) Spike-wave from stimulation of reticular core. Arch. Neurol. 11: 209-218. 